\title{
Development of the Term Trauma from a Psychoanalytical Perspective
}

\author{
A Research Submitted by \\ ZeinabAbd El-Sameea’ Monir
}

January 2019 


\section{Abstract}

Due to the scarcity of the studies written about trauma theory, this research aims at traces the development of the term trauma from a psychological perspective. Besides, it provide an overview of the origins of trauma theory and its relationship with literary studies. This research uses the psychological approach. There is no firm definition of trauma, but it has been given various descriptions at various times and under different names. In conclusion, the research conspicuously finds out a psychoanalytical definition of the term trauma.

\section{المستخلص}

نظرًا لندرة الدراسات المكتوبة حول نظرية الصدمة ، يهدف هذا البحث إلى تتبع تطور مصطلح الصدمة من منظور نفسي. علاوة على ذلك ، يقدم نظرة عامة على أصول نظرية الصدمة و علاقتها بالدر اسات الأدبية. وبالتالي، فإن هذا البحث يستخدم النهج النفسي. لا يوجد تعريف ثابت للصدمة ، ولكن تم إعطاءها وصف مختلف في أوقات مختلفة وتحت أسماء مختلفة. وفي الخاتمة، يكتشف البحث بوضوح تعريفاً لمصطلح الصدمة من المنظور النفسي. 


\section{Introduction}

Etymologically speaking, the origin of the word "trauma" itself, in both English and German, is the Greek "trauma" or "wound" or an injury inflicted on a body. However, in the Freudian psychiatric heritage, it refers to an inflicted upon the mind (Caruth, Unclaimed 3). Trauma theory has held a prominent position in the literary contexts. It is the cornerstone in the post-colonial criticism that calls for the rights of those who are psychologically or sexually abused. The injury inflicted upon the mind cannot be healed on the contrary to that of the body. Thus, in contrast to the wound of the body which heal, the wound of the mind is not most likely curable.

Sigmund Freud (1856-1939) uses the concept "trauma" to describe individual trauma (Meek 2). The traumatized person does not only suffer from behavioral disorders but also from memory disorders (Meek 5). In accordance with studies on Freudian psychoanalysis, trauma cannot be grasped consciously when the original event occurs, but it reappears in such symptoms as "intrusive memories, nightmares, compulsive acting-out and flash-backs" (Meek 5). Therefore, it cannot be accessed in time or place; it is an absent experience to the individual.

Before elaborating on the details of the literary texts, it will be useful to provide an overview of the origins of trauma 
theory and its relationship with literary studies. Recently, a number of scholars working in the field of trauma studies have a similar task, tracing the origins of contemporary theories of trauma and explicating literary studies' growing fascination with theories of trauma. Among the most comprehensive works are Ruth Leys' Trauma: A Genealogy (2000) and a chapter entitled 'Why Trauma Now?' Freud and Trauma Studies" from E. Ann Kaplan's recent study Trauma Culture: The Politics of Terror and Loss in Media and Literature (2005). As any theorist tracing the development of a field inflected by psychoanalysis would, Leys and Kaplan begin with Sigmund Freud. The most significant of Freud's hypotheses for late twentieth- and early twenty-first-century theorists of trauma is his distinction between repression, which implies an action on the part of the survivor, and trauma, which instead, the survivor appeared to have no ability to control or recall consciously. Clearly, Caruth's definition of the "possession" experienced by a survivor is influenced by Freud, whose ideas she engages with frequently throughout her work.

According to the Freudian concept of trauma, Ruth Leys defines trauma in his book Trauma: A Genealogy as "an experience that immersed the victim in the traumatic scene so profoundly that it precluded the kind of specular distance necessary for cognitive knowledge of what happened" $(2000,9)$. 
The truth of the traumatic event is too close to be realized. If someone puts a written text so close to his eyes, he will not be able to read it, not because he has impaired vision, but because the text is so close to his eyes. People are involved in past traumas to the extent that they become witnesses. When trauma takes place, it is not immediately or consciously recognized by the sufferer (Vees-Gulani, Trauma 19). Only later do the effects of trauma appear in the form of symptoms associated with it, such as nightmares and obsessive or repetitive behavior. These symptoms violate the integrity and coherence of the story about the self in a way that they seem to be "lived" rather than "remembered" experiences.

The centrality and complexity of trauma is first most profoundly addressed in one of the most important and controversial work written by Sigmund Freud, Beyond the Pleasure Principle (1920).

In Beyond the Pleasure Principle, Freud states that the word trauma refers mainly to a mental injury rather than a physical one. However, it is still labeled a double wound: psychological and physical. This psychological injury results from "a mental conflict between the ego and itself during the period of incubation, rather than a conflict between the ego and the Id" (Hecklinger 8). In other words, the traumatized individual goes through a conflict between the need for self- 
esteem and the real humiliated and degraded self after the traumatic event. Freud elaborates,

There is no longer any possibility of preventing the mental apparatus from being flooded with large amounts of stimulus, and another problem arises instead - the problem of mastering the amounts of stimulus which have broken in and of binding them, in the psychical sense, so that they can then be disposed of (Pleasure 23-24).

Thus, trauma becomes "a transgression against the shield that protects an individual from the external world as well as the internal self" (Hecklinger 9).

Psychologically speaking, the traumatic experience haunts the traumatized individual and turns into an unforgettable memory chasing him like a ghost. Although the traumatized may forget the details of the traumatic event because of its heinous and unbearable nature, they can still suffer from phobias and obsessions related to that event (MacCannell and MacCannell 205).

The traumatic event is defined as "an event outside the range of usual human experience that disturbed the psyche's normal capacity for resistance;" the personal response is defined 
as "a normal response to an abnormal situation;" and trauma is described as "an unfortunate encounter between an ordinary person and an extraordinary event" (Fassin and Rechtman 87). So, the traumatized person is "fragile and fraudulent" (Fassin and Rechtman 87).

Freud begins his discussion of trauma by noting the "bewildering" fact that psychological trauma does not occur in strict correspondence to the body's experience of a life threat, that is, through the wounding of the body or a bodily injury, in fact Freud notes this, "works as a rule against the development of a neurosis" (12). People sufferingfrom traumatic neurosis are "much occupied in their waking lives with memories of their accident. Perhaps they are more concerned with not thinking of it" (13). The time that elapsed between the traumatic accident and the first appearance of the symptoms is called the "incubation period, a transparent allusion to the pathology of infectious disease" (84; 6768, translation modified).

Writing about trauma annihilates itself since an accurate and a completely detailed description of trauma can never be guaranteed. When visual and mental images are translated into words, the story necessarily loses some aspects of the truth. The traumatic event which represents an abnormal phenomenon needs to be integrated into the sufferer's past memories. In whatever way trauma is survived or coped with by the victim, 
he goes through an experience that renders the relationship between memory and narrative a sophisticated one. Kelly K. Hecklinger states, "In the experience of trauma, attempting to share it and recreate it, an impasse between speech and silence is reached. It has been argued that victims, in the attempt to communicate their autobiographical narratives of trauma, create fictions instead" (11).

Consequently, narrating the story of personal suffering is a maneuver by the traumatized psyche to assimilate the traumatic event and grasp the unfathomable. To rebuild bridges between oneself and the world, the survivor should tell his story. In this connection, the role of literature, and particularly narrative, "emerges above all other outlets for pains" (Hecklinger 11). Although, writing embodies an outlet for pains, however, it is not only a source of relief to the traumatized individual, but also it is a medication to him. In the midst of psychic trauma, the role of narrating one's own unbearable pains figures eminently as a ray of hope, consolation and consolidation. This is why writing about one's trauma is regarded as both literature and therapy at the same time.

\section{Importance of the Research}

The importance of this research lies in the scarcity of the studies written about trauma theory. As Susannah Radston refers to in her article "Trauma Theory: Contexts, Politics, Ethics" 
"though there are repeated references to this theory, its provenance and reach are, however, rarely traced" (2).

\section{Methodology of the Research}

This research uses the psychoanalytical approach to develop the development of the term trauma.

\section{Setting the Problem of the Study}

There is no firm definition of trauma, but it has been given various descriptions at various times and under different names. In its most general definition, trauma describes an overwhelming experience of sudden or catastrophic events in which the response to the event occurs in the often delayed, uncontrolled repetitive appearance of hallucinations and other intrusive phenomena.

Since the late Victorian epoch, three types of trauma have been distinguished: psychic trauma in the late Victorian age (1837-1901), war neurosis after the First World War and sexual trauma in the modern era. The first attempts to study trauma is initiated by theories about hysteria in the Victorian age. The second wave of studies follows the First World War and examines what has become known as "Gulf War Syndrome". The third endeavor to inspect trauma is closely related to Feminism since it deals with violence against women in the current period (Horvitz 12). 
The suffering of the traumatized is evidence that they still enjoy some traces of humanity; their humanity struggles against their own brutality. Fassin and Rechtman write, "Some element of humanity inexorably resists dehumanization, and it is this humanity that the trauma of the survivors manifests" (20). So, regardless of any moral obligations, trauma is not restricted to the victims of atrocities. It includes individuals who experience traumatic events and consequently suffer such traumatic symptoms as flashback memories.

In her book, Unclaimed Experience Trauma, Narrative and History, Cathy Caruth stresses the element of memory when she defines trauma. Trauma is defined as "an overwhelming experience of sudden or catastrophic events in which the response to the events occurs in the often delayed, uncontrolled repetitive appearance of hallucinations and other intrusive phenomena" $(1996,11)$. The effect of the traumatic experience is gained through remembering it. There is "a time lapse" between the event and the traumatic experience.

So, trauma is not realized in the original event but the echo of this traumatic experience lasts to be heard and exercised by the one group with the same ethnic, racial, gender, sexual or economic background. This leads to "a post-traumatic culture". As Caruth suggests, "the historical power of trauma is not just that it is only the experience that is repeated after its forgetting, 
but that it is only in and through its inherent forgetting that it is first experienced at all" $(1994,17)$. Thus, one can argue that this traumatic experience is passed to other people of the same racial or ethnic background even if they did not experience the original event. In so doing, they become a unified group with an identity formed according to the traumatic experience. Consequently, the present becomes a mirror of the past.

Moreover, Charles R. Figley's Trauma and Its Wake (1986) introduces a good discussion of the history of the notion and for recent attempts define it. Also, trauma theory is best tackled by Cathy Caruth, Shoshana Felman, DoriLaub, and Dominick LaCapra. Their ideas all derive to a large extent from Freudian conceptions of memory and trauma, and they all emphasize the temporal aspects of psychic trauma: Caruth, for instance, describes the traumatic encounter as "a break in the mind's experience of time" (61). Implicit in this conception of trauma, as well, is the assumption that trauma is an individual and private phenomenon. They all suggest that trauma manifests itself primarily as a loss of language, coupled paradoxically with the compulsion to talk about that loss. The corollary of this point is that the "cure" for traumatic memory disorders is some variant of the talking cure: Dori Laub, for instance, argues that therapy is "a process of constructing a narrative, of 
reconstructing a history and essentially, of reexternalizing the event" (Felman and Laub 69).

Additionally, in Testimony: Crises of Witnessing in Literature, Psychoanalysis, and History, a book written by Felman, a literary critic, in collaboration with DoriLaub, a psychoanalyst, depicts the twentieth century as "a post-traumatic century, a century that has survived unthinkable historical catastrophes".

Moreover, the traumatic consequences of these accidents the characters had gone through are still actively evolving in the character's life. This becomes evident in the very ability to sustain and continue life after traumatic events transfer it into a radically unique and solitary burden. Then, comes the time for revelation. It is a time for speaking up, being heard, listening to be heard and telling the untellable stories. It is the talks to that should be replaced with talks with. It is the time traumatized share their memories with their children who are indifferent to these narratives.

The author of Literary Trauma: Sadism, Memory, and Sexual Violence in American Women's Fiction, Deborah M. Horvitz differentiates between political or cultural trauma on one hand and psychological or personal trauma on the other hand. Horvitz defines cultural or political trauma as "an officially sanctioned, sadomasochistic system of oppression in 
which a targeted group, perceived by the dominant culture as an obstacle to the goals of the existing hegemony, are tortured, imprisoned or killed" (1).

Conversely, Horvitz uses the term psychological trauma to describe "sadomasochistic violence against a designated victim, who is personally known by her assailant" (Emphasis in the original; 11). Psychologically traumatized victims include sufferers from "domestic abuse and incest" (Horvitz 11). Thus, both cultural trauma and psychological trauma melt together in the crucible of the traumatic experience. It is important to mention in this context that Fassin and Rechtman combine psychological trauma and cultural trauma under the umbrella of the following definition:

Trauma has become a major signifier of our age. It is our normal means of relating present suffering to past events. It is the scar that a tragic event leaves on an individual victim or on a witness - sometimes even on the perpetrator. It is also the collective imprint on a group of a historical experience that may have occurred decades, generations, or even centuries ago. (XI)

In order to cope with their wounds, trauma survivors need to integrate these tormenting memories into their past exactly as 
individuals are asked to integrate their painful memories into their life stories in psychotherapy. In other words, they have to accept these memories as part of their own history.

This research scrutinizes Freud's intuition of, and his passionate fascination with, traumatic experiences. If Freud turns to literature to describe traumatic experience, it is because literature, like psychoanalysis, is interested in the complex relation between knowing and not knowing. It is the specific point at which knowing and not knowing intersect and the language of literature precisely meet with the psychoanalytic theory of traumatic experience.

The research explores the complex ways that knowing and not knowing are entangled in the language of trauma and in the stories associated with it; the story of two people bonded in and around their respective traumatic experiences. If traumatic experience, as Freud indicates, is an experience that is not fully assimilated as it occurs what returns to haunt the traumatized person in Freud's primary example of trauma is not just any event but, significantly, the shocking and unexpected occurrence of an accident.

People in the current Western world have become familiar with extremely violent scenes and narratives which are part and parcel of their daily life. This is why they are diagnosed to be suffering from psychic trauma. The contemporary world 
"is dubbed a traumatic age, and identity is determined by suffering and survival" (Meek 6)

Teresa Godwin Phelps, in her comparative study of truth commissions, emphasizes the need for a victim to reclaim her "ability to articulate her pain" (5): "the turning of inchoate pain and grief into a narrative gives the victim control and distance from the traumatic event and empowers the victim to get on with his or her life" (57).

Additionally, Jonathan Cohen, "Structural Consequences of Psychic Trauma: A New Look at Beyond the Pleasure Principle," published in International Journal of Psychoanalysis (1980) discusses in details the topic of trauma. Besides, Abram Kardiner with Herbert Spiegel tackle trauma in, War Stress and Neurotic Illness, (1947). It is important to mention that the selfpsychological approach is expressed in the essays of Richard B. Ulman and Doris Brothers, The Shattered Self: A Psychoanalytic Study of Trauma (1988). Finally, Robert Jay Lifton has a marvelous treatment of trauma in, "Survivor Experience and Traumatic Syndrome"; and Charles Marmar, "The Dynamic Psychotherapy of PTSD" (1991).

Abreaction is the name given by Freud to describe his theory of treating traumatized survivors. In this method, the traumatized finds an outlet for his painful memories when he 
reiterates his traumatic experience to the listener. Through his reiteration, the survival experiences a kind of catharsis. This repetition enables the traumatized person to master the source of his anxiety in a retrospective manner by erasing the source that causes traumatic neurosis (Costhwaite 62). When a traumatic event occurs, it is only recognized later in a belated way. Although the individual survives the traumatic event and goes through it physically unharmed, he cannot escape the psychological consequences (Costhwaite 64). With the help of testimony, the survival remembers his agonizing traumatic memories, and thus they can be eliminated (Parr 18).

Writers of trauma use the past to reflect on the proceedings of the present. So, this research claims that the past is used to clarify the present. Since trauma is an unspeakable experience, it resists verbal articulation. The experience is too unspeakable to be represented. Traumatic narrative embodies the conflict between two forces: the necessity to remember the traumatic past to bear witness to it and the importance to forget this past to avoid its horrors. The traumatic event cannot be assimilated into the conscious and reminds repressed and forgotten in the unconscious. When the traumatic event can be translated into words in a narrative, it can be encompassed as a part of the survivor's narrative. At the same time, the narrative is necessarily a pale portrait of the real or original event. This past 
cannot be described as purely past because it is really a permanent present reified in the repetitive intrusion of the past on the present, leaving a strong impact on the traumatized memory and identity.

There will be a guiding theoretical voice in the analysis of testimony. Because trauma involves an inability to assimilate the experience, andbecause the survivor experiences trauma as a loss of control, according to Laub, creating a narrative about the traumatic event provides an essential site of power and control for the survivor:

To undo this entrapment in a fate that cannot be known, cannot be told, but can only be repeated, a therapeutic process - a process of constructing a narrative, of reconstructing a history and essentially, of re-externalizing the event - has to be set in motion. This reexternalization of the event can occur and take effect only when one can articulate and transmit the story, literally transfer it to another outside oneself and then take it back again, inside. (69)

Since trauma can affect individuals, this is called personal trauma. In personal trauma, individuals who have not gone through direct traumatic experiences still can see the world via a 
traumatic perspective whether consciously or unconsciously. Consequently, trauma extends to the witness of trauma as well as the traumatized himself. In "The Intrusive Past: The Flexibility of Memory and the Engraving of Trauma," Bessel A. van der Kolk and Onno van der Hart distinguish between traumatic memory, which emerges without, and sometimes against, the survivor's will, and narrative memory, which becomes a means through which survivors can contain and take control of their experiences. Normally, Van Der Kolk and Van Der Hart assert, experiences can be recalled and narrated, and consequently, can "be integrated into existing meaning schemes" (175).

However, because, according to Van Der Kolk and Van Der Hart, traumatic events cannot be experienced at the time of their occurrence, they are instead "contained in an alternate stream of consciousness" (168), where, as Caruth and others argue, the memories "are largely inaccessible to conscious recall and control" (Trauma 151). Subsequently, memories of traumatic events emerge unconsciously, often in the form of "somatic sensations, behavioral reenactments, nightmares, and flashbacks" (Van Der Kolk 172). At a distance from the event itself, the survivor eventually is forced to remember, to confront, indeed, to truly experience for the first time, events that have psychologically scarred her. 
Caruth and Felman embrace deconstructive criticism in their approach to trauma. The traumatic memories are expressed obliquely through "gaps, silences, erasures and distorted memories in the discourse of victims of, and witness to historical catastrophe" (Meek 20). These gaps in memory are the equivalent to aporias and marginal points in the literary text in deconstructive criticism, and as a result, they create indeterminacy of meaning. These points of contradiction in the text are focused on and are regarded as a repressive force within it, a notion derived from psychoanalysis and utilized by Caruth and Felman to interpret traumatic memories. Aporias, contradictions and marginal points help to unravel what the text represses within its structure of meaning.

As post-colonial criticism calls for the rights of the colonized, queer theory upholds those of gays and lesbians, and feminism supports those of women, trauma theory defends the rights of the psychologically traumatized. The process of analysis in this research depends on two pillars: psychic trauma and diasporic trauma. Those suffering from these two types of trauma are stigmatized and humiliated.

Moreover, this research discusses the influence of trauma that leaves a permanent impression of rage and anger on the psyches of the four works' protagonists in an attempt to prove that although recalled reminiscences are distorted and 
discontinuous yet they facilitate the psychological redemption of afflicted trauma survivors. Although literary studies has clearly taken an interest in trauma theory, literary trauma studies is a growing area ofinterest to which this research seeks to contribute by analyzing a number of novels that have not yet been extensively linked with theories of trauma.

Traumatic narratives are often silenced and repressed by the social norms that resist any tendencies to disgrace the society. Moreover, language seems handicapped in front of recounting an ineffable or incommunicable experience. So, narration is difficult because of this language barrier and because of breaching the social standards. Indeed, trauma challenges the human capacity to grasp its nature that defies the survivor's ability to cope with and assimilate. Literarily speaking, literary criticism practices a vital role in revealing how a traumatic experience can be narrated in a literary text in spite of the language barrier (Robson 13). This role is essentially a literary one. This is why Caruth illustrates that trauma must "be spoken in a language that is always somehow literary: a language that defies, even as it claims, our understanding" (Unclaimed 5). While trauma survivors need to be understood and listened to, their suffering keeps out of reach and beyond the grip of mind. 
A comparison can be drawn between a real wound or injury of the body and a psychic crack of the soul. Trauma is not only a crack in the psyche, but also it is a rupture in knowledge about the nature of the traumatic experience. Therefore, understanding a traumatic narrative requires an ability to read the implicit images in the text, to frame a portrait that is full of gaps and to uncover the repressed feelings buried in the hidden recesses of the victim. Since this is a literary task, it necessitates a textual analysis of the narrative to fill the gaps within it. Through writing traumatic narratives, writers seek "self-expression" and try to "break out of the silence in which they were imprisoned" (Robson 14). So, they write fiction. Nevertheless, they prefer writing fiction because trauma cannot be grasped by the traumatized in order to express it. Consequently, the traumatic experience remains in the unconscious with some reminiscences that are mixed and dim (Robson 14-15).

As for trauma theory, Caruth relies mainly on Freud, Paul de Man (1919-1983) and Jacques Lacan (1901-1981). She attempts several times to draw conclusion from the psychiatrist and interviewee, Robert J. Lifton, to support her perspective that trauma can never be immediately recognized at the time of its occurrence (Vees-Gulani, Trauma 23). 
Additionally, trauma is defined as the corollary of a "sound of the mind - the breach of the mind's experience of time, self, and the world ... an event that... is experienced too soon, too unexpectedly, to be fully known and is therefore not available" (Carth, Unclaimed 4).

Moreover, trauma is not realized in the original event, but the voice of the wound is heard and repeated in the traumatic experience later on. The traumatic experience is so depressive that it cannot be assimilated. It remains unknown in the original event (Caruth, Unclaimed 4). Early, Freud argues that the main source of trauma is a violent sexual violation committed against the patient at an earlier time. Later on, Freud changes his mind by highlighting that the violent violation can be sexual or otherwise. This violation can turn into trauma only when it emerges again after a period in the form of reliving the traumatic experience that is revived by a second event. The victim re-experiences the traumatic event in the form of repetitive nightmares that affect him involuntarily (Hecklinger $8)$.

Perhaps the significance of the title of Caruth's book, Unclaimed Experience: Trauma, Narrative, and History, is that trauma does not belong to individuals, but it belongs to the collective unconscious of people. Traumatic experiences are 
"unclaimed" which means "unlocatable" due to their pervasive influence on all people (Vees-Gulani, Trauma 19).

However, this research argues that trauma is not simply an effect of destruction but also, fundamentally, an enigma of survival. It is only by recognizing traumatic experience as a paradoxical relation between destructiveness and survival that we can also recognize the legacy of incomprehensibility at the heart of traumatic experience.

Moreover, it is not easy to define the term trauma. Shoshana Felman defines trauma as "an event that has no beginning, no ending, no before, no during and no after" (69). Some fiction characters suffer a terrible trauma that conspicuously affects their psyches. They are traumatized by an accidental death. However, they succeed in overcoming their traumas and survive.'Where men and women are forced to endure terrible things at the hand of others-whenever, that is, extremity involves moral issues- the need to remember becomes a general response. Spontaneously, they make it their business to record the evil forced upon them. ... Here, and in similar situations, survival and bearing witness become reciprocal act. (Terrence Des Pres, The Survivor, 19976).

According to Cathy Caruth's oft-cited definition of trauma, "the event is not assimilated or experienced fully at the time, but only belatedly, in its repeated possession of the one 
who experiences it. To be traumatized is precisely to be possessed by an image or event" (Trauma 4-5). Several theorists, including Caruth, argue that a trauma that has not been understood and cannot be consciously recalled must, nonetheless, be transformed into narrative, which "allows the story to be verbalized, communicated, to be integrated into one's own, and others', knowledge of the past" (Trauma 153). Ironically, Caruth also suggests that transformation is an impossible task. Caruth herself seems to privilege the power of the traumatic memory over the survivor's capacity towork through that memory; the event can never be understood and instead presents an "affront to understanding" (Trauma 154).

In her book Treatments: Language, Politics, and the Culture of Illness, Lisa Diedrich deals with the experience of illness as a traumatic experience, whether the disease is severe, chronic or fatal like cancer. So, illness narrative is peculiar to the modern and post-modern societies. In these narratives, language turns crippled; it fails to record the extremity or severity of the anguish the characters have to endure (Diedrich VIII).

Consequently, reading becomes a healing tool that helps the literary other to be identified with the self. In illness narratives, suffering is the cornerstone along with the ideas of loss, failure and loneliness. In this literary genre, the author 
moves deeply into the world and profoundly into the self. Diedrich reaffirms the disability of language to reveal or unfold the pains of trauma, simply because language is finite, but suffering is infinite. The incommunicability of language consists in its incapacity to reflect the intensity of the pain (Diedrich 111).

Freud's theory that the etiology of hysteria can be traced back to sexual abuse is widely known as the seduction theory (Fassin and Rechtman 32). Attaching hysteria to sexual trauma in the form of rape is really an accusation against a patriarchal society that directs its violence towards women and children. Suffering from guilt feelings, the society hushes up such revelations about sexual trauma. Simply speaking, Freud discusses the unconscious fantasies and desires separately from the women's real experiences (Horvitz 13-14). He claims that the traumatized is already ill with the sexual before confronting the sexual traumatic event. Whenever discussion of sexual trauma, it gets silenced by the society. Hushing up arguments over sexual trauma seems to be systematic in a patriarchy where women are routinely traumatized, and where denial and repression are active factors. For example, the male violence against women is overlooked by the society as if it were not prevalent in its culture (Freedman 113). 
Sexual trauma can be read psychologically. Women can respond hysterically in their later life to earlier violent incidents. Trauma turns into an ordinary or everyday concept. It includes people who go through or witness traumatic events. Their agonizing memories can appear in implicit or explicit symptoms either physically or psychologically. In his modification of seduction theory, Freud claims that "the sexual is already traumatic in the unconscious" (Fassin and Rechtman 32).

\section{Results}

In conclusion, trauma is a mental injury that is difficult to heal in contrast with a serious physical injury that can be cured after a relatively short period. It is a pathological case that is hard to assimilate into normal life. the revealed message is not only about the direct violence that the individual experiences, but also it is about the unknown future repercussions that appear after the incubation period. Consequently, trauma is a term that is used in trauma studies or traumatology to introduce an old concept from a modern angle. It used to indicate a physical injury, but since the late nineteenth century, it has come to refer to a psychic wound. However, today, this new perspective of trauma is reinforced. 


\section{Works Cited}

Caruth, Cathy. Unclaimed Experience: Trauma, Narrative, and History. Baltimore: Johns Hopkins UP, 1996.

Fassin Didier and Richard Rechtman. The Empire of Trauma: An Inquiry into the Condition of Victimhood. Trans. Rachel Gomme. Pronceton: UP, 2009. Print.

Felman, Shoshana and DoriLaub, M.D. Testimony: Crises of Witnessing in Literature, Psychoanalysis and History. New York: Rout ledge, 1992.

Figley, Charles R., ed., Trauma and Its Wake. 2 vols. New York: Brunner-Mazel, 198586.

Freud, Sigmund. Beyond the Pleasure Principle. Trans. James Strachey. NY: W.W. Norton, 1961. Print.

Kaplan, E. Ann. Trauma Culture: The Politics of Terror and Loss in Media and Literature. New Brunswick, NJ: Rutgers UP, 2005. 
Leys, Ruth. Trauma: A Genealogy. Chicago: University of Chicago Press, 2000.

MacCannell, Dean and Juliet Flower MacCannell. "Violence, Power and Pleasure. A Revisionist Reading of Foucault from the Victim Perspective." Ramazanoglu 203. 38.

Meek, Allen. Trauma and Media: Theories, Histories, and Images. NY: Routledge, 2010. Print.

Susannah, Radstone. "Trauma Theory: Contexts, Politics, Ethics". Paragraph. 30:1, 2007. 